\title{
OS CONSENSOS SOBRE OS ASPECTOS PEDAGÓgICOS DE ESPECIALISTAS/ACADÊMICOS NO ENSINO DO CONTEÚDO LUTAS NAS ESCOLAS
}

THE CONSENSUS ON THE PEDAGOGICAL ASPECTS OF SPECIALISTS/ACADEMICS IN THE TEACHING OF CONTENT STRUGGLES IN SCHOOLS

CONSENSO SOBRE LOS ASPECTOS PEDAGÓGICOS DE LOS ESPECIALISTAS/ACADÉMICOS EN LA ENSEÑANZA DE LAS LUCHAS DE CONTENIDO EN LAS ESCUELAS

\section{Diego Luz Moura \\ (iD) 9}

Doutor em Educação Física (UGF)

Docente do programa de pósgraduação da Universidade Federal do vale do São Francisco (Univasf) lightdiego@yahoo.com.br

\section{Phillipe Williams de Souza}

Targino

(iD) 9

Licenciado em Educação Física Discente da Universidade Federal do Vale do São Francisco (Univasf)

phillipetargino@gmail.com

\section{João Gabriel Eugênio Araujo (iD) 9}

Mestre em Ciências (Univasf) Docente do Instituto Federal de Pernambuco (IFPE) joao.araujo@afogados.ifpe.edu.br

\begin{abstract}
Resumo
O objetivo deste artigo é identificar os consensos sobre os aspectos por especialistas/acadêmicos pedagógicos no ensino do conteúdo lutas nas escolas. A metodologia utilizada foi a técnica delphi. Esta metodologia busca um consenso de especialistas através da utilização de entrevistas abertas e posteriormente, questionários para a identificação dos consensos. $\mathrm{O}$ critério de inclusão dos participantes foi: a) possuir pelo menos a 2(dois) anos com experiência no ensino da disciplina de lutas na universidade e; b) possuir 10 anos como praticante de alguma modalidade de lutas. Concluimos que os especialistas reforçam temas que são encontrados na literatura da área e indicam outros pontos que merecem reflexão. Neste sentido, estes consensos podem ser entendidos como uma agenda para se pensar o ensino das lutas.
\end{abstract}

Palavras-chave: Educação física escolar. Ensino. Lutas.

Recebido em: 21 de abril de 2021 .

Aprovado em: 27 de julho de 2021.

Como citar esse artigo (ABNT):

MOURA, Diego Luz; TARGINO, Phillipe Williams de Souza; ARAUJO, João Gabriel Eugênio. Os consensos sobre os aspectos pedagógicos de especialistas/acadêmicos no ensino do conteúdo lutas nas escolas. Revista Prática Docente, v. 6, n. 2, e061, 2021.

http://doi.org/10.23926/RPD.2021.v6.n2.e062.id1140 


\section{Abstract}

The purpose of this article is the consensus on the pedagogical aspects of specialists/academics in the teaching of content struggles in schools. The methodology used was the delphi technique. This methodology seeks a consensus of experts through the use of open interviews and later, questionnaires to identify consensus. The inclusion criteria of the participants were: a) to have at least 2 (two) years with experience in teaching the discipline of fights at the university and; b) have 10 years as a practitioner of some type of fighting. We conclude that the specialists reinforce themes that are found in the literature of the area and indicate other points that deserve reflection. In this sense, these consensus can be understood as an agenda for thinking about the teaching of struggles.

Keywords: School physical education. Teaching. Fights.

\section{Resumen}

El propósito de este artículo es Consenso sobre los aspectos pedagógicos de los especialistas / académicos en la enseñanza de las luchas de contenido en las escuelas. La metodología utilizada fue la técnica delphi. Esta metodología busca el consenso de expertos mediante el uso de entrevistas abiertas y posteriormente, cuestionarios para identificar consensos. Los criterios de inclusión de los participantes fueron: a) tener al menos 2 (dos) años de experiencia en la enseñanza de la disciplina de las luchas en la universidad y; b) Tener 10 años como practicante de algún tipo de lucha. Concluimos que los especialistas refuerzan temas que se encuentran en la literatura del área e indican otros puntos que merecen reflexión. En este sentido, estos consensos pueden entenderse como una agenda para pensar en la enseñanza de las luchas.

Palabras clave: Educación física escolar. Enseñando. Peleas. 


\section{INTRODUÇÃ̃o}

As lutas fazem parte dos conhecimentos adquiridos pela humanidade através do tempo que foram motivados por distintas razões como a busca pela sobrevivência, a realização de exercícios físicos, o treinamento militar, a defesa pessoal e etc. E pelo fato de se configurar como um conhecimento da cultura corporal desenvolvida pela humanidade deve fazer parte do currículo escolar para que seja transmitida para as futuras gerações (MOURA et al., 2017).

No campo da educação física, o conteúdo de lutas sempre foi compreendido como um conteúdo legítimo. Já em 1997, na publicação dos Parâmetros Curriculares Nacionais (PCN), a luta já estava citada nos blocos de conteúdo. Todavia, esse conteúdo ainda é pouco explorado por grande parte dos professores de educação física (RUFINO; DARIDO, 2012). Isso ocorre porque de alguma forma, a abordagem dos esportes ainda tem certa hegemonia dentre os outros conteúdos como as lutas (MOURA et al., 2017).

Moura et al. (2019) analisaram a produção sobre as lutas na educação física escolar no período de 2005-2015. Apontaram que os principais temas apresentados pela literatura neste período há os aspectos metodológicos, os estereótipos da violência e a necessidade de melhoria na formação docente. No mesmo sentido, Antunes et al. (2017) em um levantamento da produção no período de 1997-2011, apontaram dados semelhantes ao indicar as estratégias de ensino, a avaliação da aprendizagem, seleção e organização de conteúdo e a formação de professores como temas fundamentais para a discussão sobre o ensino das lutas na escola. Podemos perceber que tanto na análise da literatura de Moura et al. (2019), quanto em Antunes et al. (2017), a organização pedagógica e a formação de professores são temas que se destacam.

A formação inicial tem um papel fundamental em proporcionar aos futuros professores a segurança necessária para abordar esse conteúdo nas aulas (MOURA et al., 2019). A formação inicial precisa ser reformulada e apresentar uma organização do ensino que dialogue com as necessidades da escola (MOURA et al. 2017; FONSECA; FRANCHINI; DEL VECCHIO, 2013).

Um outro aspecto apontado pela literatura refere-se a sistematização dos conteúdo do ensino das lutas. Alencar et al. (2015) e Moura et al. (2017) afirmam o conteúdo lutas precisa de maiores esforços para que esse conteúdo seja tratado com um olhar mais pedagógico na escola. 
A falta de materiais pedagógicos é outro fator que limita a abordagem das lutas na escola. Moura et al., (2017) apontam que ainda são poucos os materiais que produzem análises mais relacionadas com as estratégias de ensino deste conteúdo nas aulas de educação física.

No cenário recente, a Base Nacional Comum Curricular (BNCC) (BRASIL, 2017), inseriu de forma normativa as lutas como um conteúdo da educação básica. Porém, as menções à luta aparecem no documento de uma forma mais generalizada, sem um aprofundamento detalhado e estratégias de como poderia ser abordada esse conteúdo nas aulas. Essa abordagem generalista pode acabar por confundir mais do que ajudar os professores, principalmente sobre as lutas, que como vimos, ainda carecem de consensos.

Nesse sentido, Rufino e Darido (2015) acreditam que seja necessário trazer à tona as opiniões e representações de professores que estão diretamente envolvidos no ensino das aluno da educação básica. Corroboramos o argumento dos autores e acreditamos que é preciso consultar os diferentes especialistas, tanto professores pesquisadores no tema, quanto professores formadores e responsáveis pela formação inicial relacionada com esse conteúdo. Desta forma, nosso objetivo é identificar os consensos sobre os aspectos pedagógicos no ensino do conteúdo lutas nas escolas por especialistas/acadêmicos no tema.

\section{Metodologia}

Este artigo possui uma abordagem quali-quantitativa na média em que mescla elementos das duas abordagens. Por um lado, buscamos analisar os significados através da percepção dos indivíduos, mas por outro lado, identificamos as ocorrências numéricas.

Foi utilizada a técnica Delphi. Segundo Linstone e Turoff (1975) essa técnica é utilizada para estimar a probabilidade e o impacto de acontecimentos futuros e incertos. Através da técnica Delphi, busca-se um consenso de especialistas por meio da utilização de entrevistas abertas com uma amostra reduzida e, posteriormente, a construção de questionários para identificar consensos.

Está técnica utiliza-se de "rounds", que são as fases de respostas da entrevista e/ou do questionário. Geralmente, são utilizados de dois a três rounds para se obter os indicadores de consenso. Porém, pode-se utilizar quantos rounds forem necessários para a construção do questionário.

Os participantes foram professores doutores, que ministram a disciplina de lutas em universidades. Os critérios de seleção foi: a) possuir pelo menos a 2(dois) anos com experiência 
no ensino da disciplina de lutas na universidade e; b) possuir 10 anos como praticante de alguma modalidade de lutas.

A seleção dos participantes ocorreu através da técnica de bola de neve, onde os indivíduos selecionados convidam novos participantes da sua rede de conhecidos, utilizando uma cadeia de referências. A técnica de bola de neve é útil para estudar determinados grupos difíceis de serem acessados (BERNAND, 2005). Iniciamos a seleção dos entrevistados através de 2 professores já conhecidos em nossa rede de contato e estes indicaram os próximos.

Na seleção dos participantes realizamos a técnica de bola de neve e entramos em contato com inúmeros docentes que atendiam ao critério da pesquisa. Porém, apenas 3 professores aceitaram participar da pesquisa. Para pontuar como concordância, foi adotado o critério de 2/3 dos professores assinalarem os itens como "concordo totalmente e parcialmente". Evidentemente, as respostas que foram distribuídas entre os pontos neutros ou se dissiparam não havendo predominância, não foram contabilizadas.

Os participantes atenderam plenamente os critérios da pesquisa de serem formados em educação física com titulação de doutor e mais de 10 anos de experiencia em alguma modalidade de lutas.

Neste sentido, no primeiro round foi realizado a entrevista aberta, e em seguida nos próximos rounds, acontecerá a conferência de consensos para encontrar os consensos. Após essa etapa, construímos um questionário do tipo Likert com 5 pontos. A "escala Likert" ou "escala de Likert" é um tipo de escala de resposta psicométrica usada habitualmente em questionários, e é a escala mais usada em pesquisas de opinião (LIKERT; RENSIS, 1932). Os dados foram analisados através de análise estatística descritiva simples.

\section{RESUltAdOS E DISCUSSÃO}

Nesta seção apresentamos os resultados provenientes dos questionários aplicados para os 3 professores participantes da pesquisa. Os resultados estão dispostos em forma de porcentagem em cada item. Foi considerado consenso quando as respostas apresentaram uma concordância de pelo menos $2 / 3$ entre os participantes. 
Quadro 1 - As contribuições do conteúdo lutas para os alunos

\begin{tabular}{|c|c|c|c|c|c|}
\hline Item & $\begin{array}{l}\text { Concordo } \\
\text { Totalmente }\end{array}$ & $\begin{array}{c}\text { Concordo } \\
\text { Parcialmente }\end{array}$ & $\begin{array}{c}\text { Não } \\
\text { Concordo, } \\
\text { nem } \\
\text { discordo } \\
\end{array}$ & $\begin{array}{c}\text { Discordo } \\
\text { Parcialmente }\end{array}$ & $\begin{array}{c}\text { Discordo } \\
\text { Totalmente }\end{array}$ \\
\hline $\begin{array}{l}\text { Apresentar a luta como } \\
\text { uma manifestação cultural }\end{array}$ & $33,3 \%$ & $66,6 \%$ & $0 \%$ & $0 \%$ & $0 \%$ \\
\hline $\begin{array}{l}\text { Permite estudar a história } \\
\text { da sociedade }\end{array}$ & $33,3 \%$ & $33,3 \%$ & $33,3 \%$ & $0 \%$ & $0 \%$ \\
\hline $\begin{array}{c}\text { Possibilita discutir e } \\
\text { vivenciar Valores sociais }\end{array}$ & $33,3 \%$ & $33,3 \%$ & $0 \%$ & $33,3 \%$ & $0 \%$ \\
\hline $\begin{array}{c}\text { Ensina uma noção de } \\
\text { Combate }\end{array}$ & $0 \%$ & $0 \%$ & $33,3 \%$ & $66,6 \%$ & $0 \%$ \\
\hline $\begin{array}{c}\text { Apresenta uma outra } \\
\text { Linguagem de movimento }\end{array}$ & $33,3 \%$ & $66,6 \%$ & $0 \%$ & $0 \%$ & $0 \%$ \\
\hline $\begin{array}{c}\text { Ampliar a consciência } \\
\text { crítica }\end{array}$ & $33,3 \%$ & $0 \%$ & $33,3 \%$ & $33,3 \%$ & $0 \%$ \\
\hline $\begin{array}{l}\text { Proporcionar o contato } \\
\text { Físico }\end{array}$ & $100 \%$ & $0 \%$ & $0 \%$ & $0 \%$ & $0 \%$ \\
\hline $\begin{array}{c}\text { Possibilitar o } \\
\text { conhecimento sobre o } \\
\text { corpo }\end{array}$ & $33,3 \%$ & $66,6 \%$ & $0 \%$ & $0 \%$ & $0 \%$ \\
\hline $\begin{array}{l}\text { Apresentar a luta como um } \\
\text { esporte democrático }\end{array}$ & $33,3 \%$ & $66,6 \%$ & $0 \%$ & $0 \%$ & $0 \%$ \\
\hline $\begin{array}{c}\text { Trabalhar e vivenciar o } \\
\text { Autocontrole }\end{array}$ & $0 \%$ & $33,3 \%$ & $33,3 \%$ & $33,3 \%$ & $0 \%$ \\
\hline Aumenta a Autoestima & $0 \%$ & $0 \%$ & $66,6 \%$ & $33,3 \%$ & $0 \%$ \\
\hline $\begin{array}{c}\text { Permitir o } \\
\text { Autoconhecimento do } \\
\text { indivíduo }\end{array}$ & $0 \%$ & $66,6 \%$ & $0 \%$ & $33,3 \%$ & $0 \%$ \\
\hline $\begin{array}{c}\text { Proporcionar sentimentos } \\
\text { de Compaixão e } \\
\text { Solidariedade. }\end{array}$ & $0 \%$ & $66,6 \%$ & $0 \%$ & $33,3 \%$ & $0 \%$ \\
\hline
\end{tabular}

Em relação ao primeiro ponto mencionado no questionário, foi possível observar que aspectos como: Apresentar a luta como uma manifestação cultural; Permite estudar a história da sociedade; Possibilita discutir e vivenciar valores sociais; Apresenta uma outra Linguagem de movimento; Proporcionar o contato Físico; Possibilitar o conhecimento sobre o corpo; Apresentar a luta como um esporte democrático; Permitir o Autoconhecimento do indivíduo; Proporcionar sentimentos de Compaixão e Solidariedade tiveram consenso positivo de 2/3 ou mais entre os participantes da pesquisa.

Enquanto: Ensina uma noção de combate; Ampliar a consciência crítica; Trabalhar e vivenciar o autocontrole; e Aumenta a autoestima possuíram desacordo de 2/3 dos especialistas.

Os especialistas destacam que as lutas se configuram como uma manifestação cultural. Ao afirmar isso, os especialistas reforçam a concepção de que as aulas de educação física além de possibilitar o acesso às diferentes manifestações da cultura corporal também devem refletir 
de forma crítica as relações de seus conhecimentos com a sociedade (MOURA et al., 2017; RUFINO; DARIDO, 2012).

Os especialistas concordam que o ensino das lutas, permite estudar a história da sociedade. Esta concordância está amparada na literatura da área que compreende que os conteúdos devem também ser aprofundados na dimensão conceitual (BRASIL, 1997; RUFINO; DARIDO, 2012; MOURA et al., 2017; SABINO; BENITES, 2010). Neste sentido, os diferentes conteúdos escolares precisam ser contextualizados a partir das diferentes questões sociais e históricas. Algumas lutas possuem intensa relação com a história do Brasil como a capoeira (SANTOS; PALHARES, 2010; MELO, 2011), assim como, permitem acessar os conhecimentos históricos de outras sociedades (BUENO; SILVA; CAPELA, 2012).

Os Parâmetros Curriculares Nacionais (BRASIL, 1997) demarcou a necessidade de que as aulas de educação física não ficassem presas meramente ao saber fazer (dimensão procedimental), mas apontou a necessidade de um aprofundamento nos aspectos conceituais e atitudinais. Esse último, refere-se ao terceiro aspecto de concordância dos especialistas que é sobre "discutir e vivenciar uma série de valores sociais".

Notemos que os três primeiros aspectos de concordância dos especialistas, demonstram um entendimento de que as lutas diferem das práticas realizadas nos clubes e academias, onde o foco são as técnicas de combate. Esse aspecto contribui para apresentar e aprofundar conceitos e atitudes que vão além do saber fazer.

Houve concordância em afirmar que o conteúdo lutas, apresenta uma outra Linguagem de movimento. De fato, as formas de linguagem de movimento apresentadas nas lutas podem proporcionar uma grande quantidade de novas vivências para os estudantes. De certa forma a vida cada vez mais urbana e tecnológica pode contribuir para limitar o repertório motor dos jovens. Além disso, de um modo geral, o esporte por muito tempo foi considerado o conteúdo hegemônico nas aulas de educação física (MOURA, 2012). As lutas possibilitam um tipo diferente de interação com o adversário quando comparada com outros conteúdos. De acordo com a Base Nacional Comum Curricular (2017), as lutas são definidas como disputas corporais, onde empregam-se técnicas, táticas e estratégias específicas para imobilizar, desequilibrar, atingir ou excluir o oponente de um determinado espaço, combinando ações de ataque e defesa dirigidas ao adversário. A BNCC além de citar as lutas convencionais, também sugere as lutas brasileiras (capoeira, huka-huka, luta marajoara etc.), bem como, lutas de outros países do 
mundo (judô, aikido, jiu-jítsu, muay thai, boxe, chinese boxing, esgrima, kendo etc.) devido sua diversidade e linguagem corporal diferenciada.

Outro aspecto característico da linguagem das lutas, se refere ao contato físico. Embora esse elemento carregue consigo um preconceito de ser considerado um estímulo à violência. $\mathrm{O}$ contato físico por sua vez insere noções de respeito e autocontrole que são competências importantes no contexto educacional e na vida em sociedade. Portanto é fundamental que se discutam as relações entre luta $\mathrm{x}$ briga e agressividade x violência. $\mathrm{O}$ estereótipo de violência não pode ser visto com uma barreira para o ensino das lutas, mas como um potencializador da necessidade da discussão sobre a violência na sociedade (MOURA et al., 2019; UENO; SOUZA, 2014; VASQUEZ; BELTRÃO, 2013).

Os especialistas concordaram que as lutas possibilitam o conhecimento sobre o corpo, esse tema se configurou como um dos conteúdos da educação física desde a publicação dos PCN (BRASIL, 1997) que o apontava como um dos blocos de conhecimento juntamente com esportes, lutas, danças, jogos e atividades rítmicas e expressivas. Para os especialistas, o ensino das lutas pode fazer os estudantes entenderem melhor as transformações do corpo. Além disso, inserem as noções de força, coordenação motora, lateralidade, dentre outros aspectos físicos e motores.

O consenso também ficou evidente ao apontarem a necessidade de relacionar a luta como um esporte democrático. O acesso às lutas, muitas vezes, envolve o ingresso em escolas de lutas, que possui um custo financeiro. Todavia, os especialistas compreendem que este acesso pode ser facilitado pela educação física escolar, possibilitando superar as limitações dos estudantes. Nesse sentido, é preciso que as estratégias desenvolvidas durante as aulas permitam uma adaptação dos espaços e recursos.

Os especialistas concordaram que as lutas permitem o Autoconhecimento do indivíduo e proporciona sentimentos de Compaixão e Solidariedade. Este consenso refere-se ao fato que a vivência das lutas está associada a incorporação de uma série de preceitos e filosofias que demarcam hierarquia, respeito e outras competências socioemocionais (UENO; SOUZA, 2014).

Os especialistas não tiveram consenso sobre o conteúdo luta ensinar uma noção de combate. A falta de consenso está relacionada um entendimento pedagógico indicado anteriormente pelos especialistas nas outras assertivas. Além disso, como profissionais experientes nas lutas, compreendem que o número reduzido de aulas e de estímulos durante as 
aulas são insuficientes para desenvolver uma noção de combate de maneira eficaz. As lutas na escola embora apresente o acervo cultural que envolve as diferentes modalidades não são capazes de promover uma maior imersão nos alunos. Devido a estes motivos também não houve consenso sobre os itens trabalhar e vivenciar o autocontrole e aumenta a autoestima.

O item ampliar a consciência crítica não possuiu acordo entre os especialistas. A ideia de ampliação da consciência crítica é um tema mais amplo da escola e não apenas específico da educação física, o que pode ter sido o motivo dessa falta de consenso.

Quadro 2 - As dificuldades do ensino de lutas na escola

\begin{tabular}{|c|c|c|c|c|c|}
\hline Item & $\begin{array}{c}\text { Concordo } \\
\text { Totalmente }\end{array}$ & $\begin{array}{c}\text { Concordo } \\
\text { Parcialmente }\end{array}$ & $\begin{array}{c}\text { Não } \\
\text { Concordo, } \\
\text { nem discordo }\end{array}$ & $\begin{array}{c}\text { Discordo } \\
\text { Parcialmente }\end{array}$ & $\begin{array}{c}\text { Discordo } \\
\text { Totalmente }\end{array}$ \\
\hline $\begin{array}{c}\text { O Conceito concreto } \\
\text { sobre o que é lutas }\end{array}$ & $66,6 \%$ & $33,3 \%$ & $0 \%$ & $0 \%$ & $0 \%$ \\
\hline $\begin{array}{c}\text { A pouca vivência na } \\
\text { formação inicial }\end{array}$ & $66,6 \%$ & $33,3 \%$ & $0 \%$ & $0 \%$ & $0 \%$ \\
\hline $\begin{array}{c}\text { A falta do conteúdo } \\
\text { na formação } \\
\text { Continuada }\end{array}$ & $66,6 \%$ & $33,3 \%$ & $0 \%$ & $0 \%$ & $0 \%$ \\
\hline $\begin{array}{c}\text { A falta de material } \\
\text { específico }\end{array}$ & $0 \%$ & $33,3 \%$ & $0 \%$ & $06,6 \%$ & $0 \%$ \\
\hline $\begin{array}{c}\text { A falta de } \\
\text { conhecimento } \\
\text { docente }\end{array}$ & $66,6 \%$ & $33,3 \%$ & $0 \%$ & $0 \%$ & $0 \%$ \\
\hline $\begin{array}{c}\text { Trabalhar com } \\
\text { Modalidades } \\
\text { Específicas de lutas }\end{array}$ & $66,6 \%$ & $33,3 \%$ & $0 \%$ & $0 \%$ & $0 \%$ \\
\hline
\end{tabular}

Os especialistas foram questionados sobre as maiores dificuldades ao se trabalhar o conteúdo lutas nas aulas de educação física. Houve consenso nos seguintes itens: O Conceito concreto sobre o que é lutas; A pouca vivência na formação inicial; A falta do conteúdo na formação continuada; A falta de conhecimento docente; e Trabalhar com Modalidades Específicas de lutas. Apenas no item: A falta de material específico, os especialistas discordaram como uma dificuldade de se atuar com as lutas na escola.

Os especialistas entraram em consenso ao serem perguntados sobre o conceito concreto sobre as lutas que é abordada na escola. Fonseca, Franchini e Vecchio (2013) realizaram um estudo com professores e nessa pesquisa ficou evidente que quase metade dos participantes não sabiam definir o conceito de lutas, para eles lutas se resumia ao confronto com o oponente ou atividade corpo a corpo sem armas.

Para Fonseca, Franchini e Vecchio (2013) muitos professores deixam de trabalhar esse conteúdo por falta de conhecimento, tanto na formação inicial como na formação continuada. Problemas na formação inicial e continuada também foram apresentados como uma barreira 
para o desenvolvimento do conteúdo lutas pelos entrevistados na presente pesquisa, ou seja, houve consenso sobre a existência desse problema.

A formação inicial é responsável por assegurar que os futuros professores se sintam seguros ao trabalhar o conteúdo lutas nas aulas de educação física. Entretanto, a qualidade dessa formação não dá ao professor a segurança necessária. Isso pode estar relacionado a um dos fatores de consenso entre os entrevistados: a falta de conhecimento docente. Essa falta de conhecimento pode estar relacionada com a falta de material didático direcionado para o trabalho dessa modalidade nas aulas de educação física. Para os entrevistados a falta de material didático específico não é um problema ao abordar o conteúdo lutas, mas é que esse material está geralmente ligado às modalidades específicas de cada luta. Nesse sentido, houve o consenso entre os entrevistados sobre o trabalho de apenas uma modalidade específica nas aulas de educação física, ou seja, o conteúdo não é mais lutas, mas judô ou boxe, por exemplo. Esse tipo de abordagem limita as possibilidades de vivências proporcionadas aos estudantes e, por consequência limitará a aula apenas às técnicas específicas de cada modalidade.

Os especialistas discordaram que a falta de material é uma dificuldade para o ensino das lutas. Outros autores já apontavam que a falta de acesso ao material oficial específico para lutas não limita sua utilização, na medida em que é possível inúmeras adaptações (MOURA et al 2017; MOURA; ANTUNES; BARBOZA, 2012). Portanto, entendemos que, por um lado, há de se reconhecer que os materiais podem limitar a experiência dos alunos, mas, por outro lado, de forma alguma impossibilita o ensino das lutas.

Quadro 3 - Elementos conceituais no ensino das lutas na escola

\begin{tabular}{|c|c|c|c|c|c|}
\hline Item & $\begin{array}{c}\text { Concordo } \\
\text { Totalmente }\end{array}$ & $\begin{array}{c}\text { Concordo } \\
\text { Parcialmente }\end{array}$ & $\begin{array}{c}\text { Não Concordo, } \\
\text { nem discordo }\end{array}$ & $\begin{array}{c}\text { Discordo } \\
\text { Parcialmente }\end{array}$ & $\begin{array}{c}\text { Discordo } \\
\text { Totalmente }\end{array}$ \\
\hline $\begin{array}{c}\text { Os conceitos e Valores das } \\
\text { Lutas }\end{array}$ & $66,6 \%$ & $33,3 \%$ & $0 \%$ & $0 \%$ & $0 \%$ \\
\hline $\begin{array}{c}\text { Apresentar as Lutas como } \\
\text { Esporte Democrático }\end{array}$ & $33,3 \%$ & $33,3 \%$ & $33,3 \%$ & $0 \%$ & $0 \%$ \\
\hline $\begin{array}{c}\text { Incentivo das Lutas à } \\
\text { Inclusão Social }\end{array}$ & $33,3 \%$ & $33,3 \%$ & $33,3 \%$ & $0 \%$ & $0 \%$ \\
\hline $\begin{array}{c}\text { Respeitar as Diferenças } \\
\text { (raça, religião, gênero) }\end{array}$ & $33,3 \%$ & $33,3 \%$ & $33,3 \%$ & $0 \%$ & $0 \%$ \\
\hline $\begin{array}{c}\text { Exibir as diversidades } \\
\text { culturais entre as lutas }\end{array}$ & $33,3 \%$ & $66,6 \%$ & $0 \%$ & $0 \%$ & $0 \%$ \\
\hline $\begin{array}{c}\text { A colaboração entre os } \\
\text { alunos durante as aulas }\end{array}$ & $33,3 \%$ & $66,6 \%$ & $0 \%$ & $0 \%$ & $0 \%$ \\
\hline
\end{tabular}




\begin{tabular}{|c|c|c|c|c|c|}
\hline $\begin{array}{c}\text { Incentivo das Lutas ao } \\
\text { Companheirismo }\end{array}$ & $100 \%$ & $0 \%$ & $0 \%$ & $0 \%$ & $0 \%$ \\
\hline $\begin{array}{c}\text { Apresentar os benefícios } \\
\text { da Luta para a sociedade. }\end{array}$ & $0 \%$ & $33,3 \%$ & $33,3 \%$ & $33,3 \%$ & $0 \%$ \\
\hline $\begin{array}{c}\text { Como as Lutas podem } \\
\text { auxiliar no trabalho } \\
\text { Corporal }\end{array}$ & $100 \%$ & $0 \%$ & $0 \%$ & $0 \%$ & $0 \%$ \\
\hline
\end{tabular}

O aspecto conceitual é uma das dimensões a ser tematizada em cada conteúdo de ensino.

No caso das lutas, esse tema possibilita discutir diferentes aspectos. Por isso foi uma das questões ofertadas aos especialistas.

Houve consenso de que os seguintes temas não podem deixar de ser tematizados aos alunos: Os conceitos e Valores das Lutas; Apresentar as Lutas como Esporte Democrático; Incentivo das Lutas à Inclusão Social; Respeitar as Diferenças (raça, religião, gênero); Exibir as diversidades culturais entre as lutas; A colaboração entre os alunos durante as aulas; Incentivo das Lutas ao companheirismo; e Como as Lutas podem auxiliar no trabalho Corporal. Apenas o item: Apresentar os benefícios da Luta para a sociedade foi identificado com discordância.

Foi consenso entre os entrevistados que ao abordar esse conteúdo, os estudantes podem desenvolver valores e, além disso, ter momentos para colocar em prática o respeito às diferenças, sejam elas de raça, religião ou de gênero. Esse é um conteúdo que deve ser vivenciado de forma democrática respeitando as limitações de cada estudante. Ao abordar o conteúdo lutas, o professor deve ser capaz de articular aspectos técnicos e movimentos próprios das lutas, incluindo e envolvendo cada estudante na prática das lutas (RUFINO; DARIDO, 2012; MOURA et al, 2019; MOURA et al, 2017).

Para Moura et al (2017) o conteúdo lutas na escola deve ir além de aspectos relacionados ao combate e às técnicas de execução proporcionando o despertar de valores éticos e morais, além da possibilidade de debater temas de urgência social. É papel da escola que os valores presentes em cada sociedade, possa ser transmitido às futuras gerações. A educação física, através do conteúdo lutas tem a capacidade de expor elementos de forma diferente dos apresentados por outros conteúdos. Um exemplo disso é a forma como as lutas auxiliam o trabalho corporal. É consenso entre os entrevistados que as lutas têm um papel diferenciado no trabalho corporal, pois contém elementos como o puxar, o empurrar, o agarrar e outros que geralmente não são incentivados durante as aulas de educação física. Permitir o contato mais 
prolongado é o que torna as lutas um conteúdo diferente e fundamental para o desenvolvimento de valores nos estudantes.

\begin{tabular}{|c|c|c|c|c|c|}
\hline Quadro 4 - Estratégias para o ensino de lutas na educação física & $\begin{array}{c}\text { Discordo } \\
\text { Item }\end{array}$ & $\begin{array}{c}\text { Concordo } \\
\text { Totalmente }\end{array}$ & $\begin{array}{c}\text { Concordo } \\
\text { Parcialmente }\end{array}$ & $\begin{array}{c}\text { Não Concordo, } \\
\text { nem Discordo }\end{array}$ & $\begin{array}{c}\text { Discialmente } \\
\text { Totalmente }\end{array}$ \\
\hline $\begin{array}{c}\text { Valorizar o Conhecimento } \\
\text { do Aluno }\end{array}$ & $0 \%$ & $33,3 \%$ & $0 \%$ & $66,6 \%$ & $0 \%$ \\
\hline $\begin{array}{c}\text { Descrever as Técnicas nas } \\
\text { aulas }\end{array}$ & $66,6 \%$ & $33,3 \%$ & $0 \%$ & $0 \%$ & $0 \%$ \\
\hline $\begin{array}{c}\text { Discussão sobre gênero, } \\
\text { classe social, cultura e } \\
\text { outros temas transversais. }\end{array}$ & $0 \%$ & $66,6 \%$ & $33,3 \%$ & $0 \%$ & $0 \%$ \\
\hline $\begin{array}{c}\text { Através de Atividades pré- } \\
\text { desportivas }\end{array}$ & $0 \%$ & $100 \%$ & $0 \%$ & $0 \%$ & $0 \%$ \\
\hline \begin{tabular}{c} 
Uso de Jogos e Brincadeiras \\
\hline $\begin{array}{c}\text { Aprofundar os Conteúdos ao } \\
\text { decorrer das aulas }\end{array}$
\end{tabular} & $0 \%$ & $33,3 \%$ & $66,6 \%$ & $0 \%$ & $0 \%$ \\
\hline $\begin{array}{c}\text { Usar os Conteúdos mais } \\
\text { comuns de cada modalidade } \\
\text { de luta trabalhada }\end{array}$ & $66,6 \%$ & $33,3 \%$ & $0 \%$ & $0 \%$ & $0 \%$ \\
\hline
\end{tabular}

Na questão 4 foi perguntado aos especialistas, no que se refere aos aspectos práticos, as melhores estratégias de se trabalhar o conteúdo lutas. Os especialistas concordaram positivamente nos seguintes itens: Descrever as Técnicas nas aulas; Discussão sobre gênero, classe social, cultura e outros temas transversais; Através de Atividades pré-desportivas; Aprofundar os conteúdos ao decorrer das aulas; e Usar os Conteúdos mais comuns de cada modalidade de luta trabalhada. Os especialistas concordaram negativamente sobre os itens: Valorizar o conhecimento do aluno; e Uso de Jogos e Brincadeiras.

Os entrevistados apontam que descrever as técnicas é uma das estratégias de ensino para esse conteúdo. É importante que os estudantes tenham contato com as técnicas de cada luta, assim, podem conhecer e diferenciar cada uma delas. Entretanto, é fundamental que essa abordagem das técnicas não tenha o mesmo foco que o desenvolvido durante o treinamento dessa modalidade. Existem formas de trabalhar a técnica de cada modalidade sem, necessariamente, empregar métodos repetitivos que geralmente são utilizados no treinamento. A rejeição sobre o ensino da técnica precisa ser superada (VAZ, 2017).

Os entrevistados apontas o uso de atividades pré desportivas como estratégia para a abordagem do conteúdo lutas nas aulas de educação física. O uso dessas atividades pode proporcionar uma forma diferente e menos repetitiva de aprendizado das lutas. Contudo, para os entrevistados, não houve consenso quanto ao uso de jogos e brincadeiras como estratégia de ensino para esse conteúdo. Para Moura et al. (2017) o ensino das lutas pode ser baseado em 
atividades desenvolvidas a partir de jogos. Para os autores essa é uma maneira diferente e eficiente na abordagem desse conteúdo, pois além de utilizar o aspecto lúdico, também é capaz de aproximar os movimentos de lutas diferentes em uma mesma atividade.

Usar os Conteúdos mais comuns de cada modalidade de luta trabalhada é outra estratégia que tem consenso entre os entrevistados. Para eles, movimentos e técnicas das lutas devem possuir uma categorização que privilegia os elementos comuns como equilibro, imobilizações e etc. este tipo de categorização tem sido cada vez mais comum no campo das lutas (MOURA et al, 2017; NASCIMENTO; ALMEIDA, 2007).

Outro ponto de consenso entre os entrevistados é a discussão sobre gênero, classe social, cultura e outros temas transversais. Não seria possível realizar essa abordagem sem se levar em consideração os conhecimentos prévios dos estudantes. Os entrevistados não conseguiram ver as correlações entre as estratégias apresentadas durante as entrevistas.

Não foi consenso entre os entrevistados que o conhecimento prévio dos estudantes deve ser valorizado como estratégia para o ensino das lutas durante as aulas. Os estudantes sempre carregam consigo um conhecimento que pode ser explorado durante as aulas, principalmente em um conteúdo que está cada vez mais presente no cotidiano das pessoas, seja através de esportes de combate como o MMA, ou com a exibição de filmes que usam as lutas como forma de entretenimento. Esse deveria ser um recurso para auxiliar as abordagens do conteúdo lutas na escola.

\section{Conclusão}

O objetivo desse estudo foi identificar os consensos sobre os aspectos pedagógicos do ensino de luta nas escolas por especialistas/acadêmicos. Foram selecionados 3 participantes doutores em educação física que atuam em universidades públicas e com extenso envolvimento nas artes marciais como praticantes.

Os participantes apresentaram uma série de consensos e lançam luzes sobre possibilidades para o ensino. Dentre os consensos, destacam-se a potencialidade das lutas como tema catalizador das discussões de diferentes aspectos conceituais e sociais. As lutas produzem oportunidades para que o professor intencionalmente introduza e aprofunde temas como a história do Brasil, racismo, religião, gênero, violência e tantos outros.

Os especialistas reforçam a necessidade de uma melhor a formação inicial no que se refere às lutas para que os futuros professores tenham mais ferramentas de sistematizar este conteúdo na educação básica. Assim como, apontam que as ações de formação continuada não 
podem prescindir da discussão sobre as lutas, na medida em que a formação inicial ainda é deficitária.

Os especialistas defendem que a falta de materiais específicos não deve ser encarada como uma barreira para utilização das lutas na escola. De fato, a escola, sobretudo pública, ainda carece de maiores infraestrutura e material. Todavia, os materiais podem ser adaptados na medida em que o objetivo da educação física não é promover uma especialização técnicas aos alunos. Inclusive os especialistas concordam que o ensino das lutas não deve ser pautado pela tematização de modalidades específicas, mas sim, de temas compartilháveis entre elas para que os alunos possam ter acesso a diferentes possibilidades e vivências.

Portanto, podemos observar que os especialistas reforçam temas que são encontrados na literatura da área e indicam outros pontos que merecem reflexão. Neste sentido, estes consensos podem ser entendidos como uma agenda para se pensar o ensino das lutas.

\section{REFERÊNCIAS}

ALENCAR, Yhla Oliveira. O. et al. As lutas no ambiente escolar: uma proposta de prática pedagógica. Movimento, Porto Alegre, v. 23, n. 3, p. 53-63, 2015.

BRASIL. Ministério da Educação. Base Nacional Comum Curricular. Brasília: MEC, 2017.

BRASIL. Ministério da Educação. Parâmetros Curriculares Nacionais. Brasília: MEC, 1997.

BUENO, Marcos Cordeiro; SILVA, Bruno Emmanuel Santana da; CAPELA, Paulo Ricardo do Canto. A capoeira como possível instrumento de práxis revolucionária: experiência no CEC Itacorubi-Florianópolis/SC. Motrivivência, Florianópolis, n. 37, p. 83-97, 2012.

FONSECA, Joel Maurício Corrêa; FRANCHINI, Emerson.; DEL VECCHIO, Fabrício. Boscolo. Conhecimento declarativo de docentes sobre a prática de lutas, artes marciais e modalidades esportivas de combate nas aulas de educação física escolar em pelotas, Rio Grande do Sul. Pensar a Prática, Goiânia, v. 16, n. 2, 2013.

LIKERT, Rensis. A Technique for the Measurement of Attitudes. In. R.S Woodworth; New York; v.22; n. 140; p.5-55, june.1932.

TUROFF, Murray. The Policy Delphi. In: LINSTONE, Harold.; TUROFF, Murray. (Editors). The Delphi Method: Techniques and Applications. Reading, MA: Addison-Wesley Publishing Company, 1975.

MELO, Vinicius Thiago. A capoeira na escola e na Educação Física. Motrivivência, Florianópolis, n. 37, p. 190-199, 2011.

MOURA, Diego Luz et al. Dialogando sobre o ensino da educação física: lutas na escola. Curitiba: CRV, 2017. 
MOURA, Diego Luz. Cultura e educação física escolar: da teoria à prática. São Paulo: Phorte, 2012.

MOURA, Diego Luz; BARBOZA, Liliane de Brito; ANTUNES, Marcelo Moreira; Entrando na roda: uma análise das dificuldades e facilidades da inserção da capoeira em escolas da rocinha. Revista Mackenzie de Educação Física e Esporte, v. 11, n. 1, 2012.

MOURA, Diego Luz et al. O Ensino de Lutas na Educação Física Escolar: Uma Revisão Sistemática da Literatura. Pensar a Prática, Goiânia, v. 22: 51677, p. 1-11, abril. 2019.

NASCIMENTO, Paulo Rogério Barbosa do; ALMEIDA, Luciano de. A tematização das lutas na Educação Física Escolar: restrições e possibilidades. Movimento, v. 13, n. 3, p. 91-110, 2007.

RUFINO, Luiz Gustavo Bonatto; DARIDO, Suraya Cristina. Pedagogia do esporte e das lutas: em busca de aproximações. Revista Brasileira de Educação Física e Esporte, São Paulo, v.26, n.2, abr./jun. 2012, p. 283-300.

SABINO, Thércio Fabio Pontes.; BENITES, Larissa Cergoni. A capoeira como uma atividade extracurricular numa escola particular: um relato de experiência. Motrivivência, Florianópolis, n. 35, dez. 2010, p. 234-246.

SANTOS, Gilbert de Oliveira; PALHARES, Leandro Ribeiro. A capoeira na formação docente de educação física. Pensar a Prática, Goiânia, v. 13, n. 3, set./dez. 2010, p. 114.

UENO, Viviane Lopes Freitas; SOUZA, Marcel Farias de. Agressividade, violência e judô: temas da educação física em uma escola estadual de Goiânia. Pensar à Prática, Goiânia, 2014.

VAZ, Alexandre. Esporte: encontro entre corpo, técnica e tecnologia. V.7, n.2.Cadernos de Formação, RBCE, 2017. 